\title{
Protótipo de um aplicativo turístico de Caruaru (PE) para a comunidade surda.
}

Prototype of a tourist application of Caruaru (PE) for the deaf community.

lara Cássia de M Florêncio. Diogo Cordeiro Cavalcanti, Luciana Lopes Freire.

Palavras chaves: acessibilidade, sistema de informação, turismo.

Resumo:

Este artigo apresenta um protótipo de um aplicativo de orientação dos espaços turísticos culturais de Caruaru (PE), para um determinado público alvo: A comunidade surda. A partir de uma análise sobre o contexto regional e características destas pessoas, pode-se compreender as necessidades da comunidade surda no que se diz respeito aos sistemas de informações existentes, como também testar as possibilidades linguísticas a serem implantadas, através de sistemas de informação mobile. O estudo dos sistemas de informação é de extrema importância para compreender como se devem organizar as informações de maneira a primar pela usabilidade, tornando o entendimento mais rápido e eficaz. Deste modo, para criar o referido protótipo de aplicativo turístico para smartphones, esta pesquisa considerou a complexidade linguística da utilização da língua brasileira de sinais (LIBRAS) no aplicativo, sendo inserida em forma de vídeo, com as legendas em português. Portanto, além de compreender as necessidades dos surdos em projetos digitais e o contexto cultural em que vivem, buscou-se planejar melhor a interface do aplicativo, a partir da distribuição e localização dos pontos turísticos da cidade de Caruaru e inserção de pictogramas representativos destes locais.

Key words: accessibility, information system, tourism

\section{Summary:}

This article presents the realization of a prototype of an application of orientation of the cultural tourist spaces of Caruaru (PE), for a certain target audience: The deaf community. From an analysis of the regional context and characteristics of these people, one can understand the needs of the deaf community regarding the existing information systems, as well as test the linguistic possibilities to be implemented through mobile information systems. The study of information systems is extremely important to understand how information should be organized so as to excel in usability, making understanding faster and more efficient. In order to create this prototype of a tourist application for smartphones, this research considered the linguistic complexity of the use of the Brazilian sign language (LIBRAS) in the application, being inserted in the form of video, with the Portuguese subtitles. Therefore, in addition to understanding the needs of the deaf in digital projects and the cultural context in which they live, we sought to better plan the interface of the application, from the distribution and location of the tourist sites of the city of Caruaru and insertion of pictograms representative of these places.

\section{Introdução}

Os surdos são minoria linguística, sendo no Brasil usuários da Língua Brasileira de Sinais (Libras). Para os surdos o processo de aprendizagem da leitura e da escrita da língua portuguesa é complicado, muitos são considerados analfabetos funcionais, pois não compreendem a língua portuguesa em sua forma escrita. Esta dificuldade em aprender a língua portuguesa se dá, pois, os surdos compreendem o mundo pela visão e a língua portuguesa é baseada nos sons fonéticos. A língua que se adequa às necessidades visuais dos surdos Brasileiros é a LIBRAS (língua Brasileira de sinais), é essencial para a sua utilização para a aprendizagem da língua portuguesa como segunda língua. Projetos que incorporam a LIBRAS facilitam a independência do surdo em tarefas em seu dia-a-dia e geram um ganho enorme na qualidade de vida dessa comunidade, como por exemplo no turismo.

Anais do 8 $\mathrm{CIDI}$ e 8 CONGIC

Guilherme Santa Rosa; Cristina Portugal (orgs.)

Sociedade Brasileira de Design da Informação - SBDI

Natal | Brasil | 2017

ISBN 978-85-212-1305-5
Proceedings of the $8^{\text {th }} \mathrm{CIDI}$ and $8^{\text {th }}$ CONGIC

Guilherme Santa Rosa; Cristina Portugal (orgs.)

Sociedade Brasileira de Design da Informação - SBDI

Natal| Brazil | 2017

ISBN 978-85-212-1305-5 
O turismo é uma atividade econômica fundamental para o Brasil, e, em especial, para o Nordeste. O turismo de Caruaru destaca-se pelo seu potencial cultural ligado à cultura popular pernambucana, a cidade possui a maior feira livre do Brasil. As festividades de São João de Caruaru também são um potencial atrativo turístico na cidade. A prefeitura de Caruaru já disponibiliza um intérprete de LIBRAS na tradução da apresentação de algumas bandas que se apresentam no São João de Caruaru, facilitando a inclusão dos surdos nessa grande festividade local. (Surdosol, 2015)

Os aplicativos para smartphone e tablet vem ganhando espaço e popularidade, estes aplicativos podem ter os mais diversos usos, isto varia de acordo com o fim a qual for proposto. Vale destacar que o aplicativo descrito neste artigo foi projetado com a finalidade de ser informacional, este supri além das demandas informacionais do público em geral as do grupo específico estudado. Como visto até então, podemos afirmar que a pesquisa tem a importância científica e social necessária além de ter importância mercadológica, já que existe um público alvo que necessita do produto final.

\section{Os Sistemas de informação e o método de Garret (2003)}

Os sistemas informacionais são formados pelos elementos das interfaces digitais em conjunto que interagem e geram resultados. Já que, "A interface de um sistema interativo compreende toda a porção do sistema com o qual o usuário mantém contato físico (motor ou perceptivo ou conceitual durante a interação) ". (Moran, 1981) apud (Silva \& Barbosa, 2010).

É primordial entender como se dá essa relação do usuário mediante o sistema, os autores 'Kim e Lee, 2005' apud 'Padovani et al, 2013' desenvolveram um modelo com quatro estágios de interação que acontecem nos sistemas digitais: percepção, navegação, execução e confirmação, que explica bem esta interação. Abaixo tabela que explica passo a passo desta interação.

Figura 1 - Tabela de atividades do usuário. Fonte: Kim e Lee (2005) apud Padovani et al (2013).

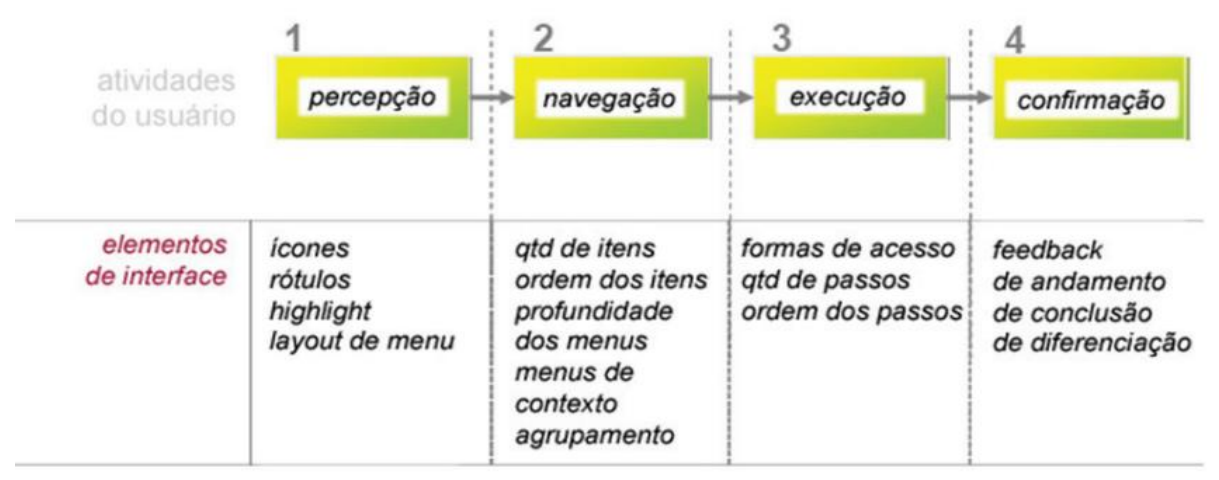

Todo esse processo acontece em segundos subconscientemente e por fim é externada, primeiramente o usuário percebe a interface gráfica e todos os elementos pertencentes a esta, durante a navegação ele percebe a quantidade de menus, itens e o contexto de agrupamentos, na etapa de execução o mesmo escolhe qual ação vai realizar. Por fim, na etapa de confirmação é onde o mesmo recebe o feedback, ou seja, a resposta do sistema em relação a tarefa executada.

A respeito disso 'Silva \& Barbosa, 2010' dissertam que "A interface com o usuário determina os processos de interação possíveis, à medida que determina o que ele pode falar 
ou fazer, de que maneira e em que ordem". É necessário entender o que cada parte da interface está comunicando ao usuário e como ele entende esta mensagem.

Sendo assim, serão descritos os requisitos que se aplicam a design mobile e que serão seguidos na realização deste projeto de interface digital. Tudo começa aqui nesta etapa, planejamento do mapa de navegação. Esta parte também pode ser chamada de Arquitetura da informação do sistema e consiste em estabelecer quais são as principais telas e as rotas de navegação.

O método de 'Garret, 2003' se divide em 5 etapas sendo elas: Estratégia, escopo, estrutura, esqueleto e superfície. No diagrama abaixo o autor destaca a superfície em primeiro plano, pois é o primeiro que o usuário vê, porém, para projetar devemos seguir o caminho inverso.

Portanto, tem-se a seguir, a descrição do método de Garret e de suas etapas projetuai $s$ para o design digital, bem como, a descrição de como ele foi aplicado para o presente estudo, conforme já dito. Considerando-se que, por se tratar da construção de um protótipo de um aplicativo foram desenvolvidas interfaces finais em formato de protótipo que precisam posteriormente serem "testadas" de modo simulado.

Figura 2 - Diagrama Metodológico de Garret. Fonte: Garrett, 2003.

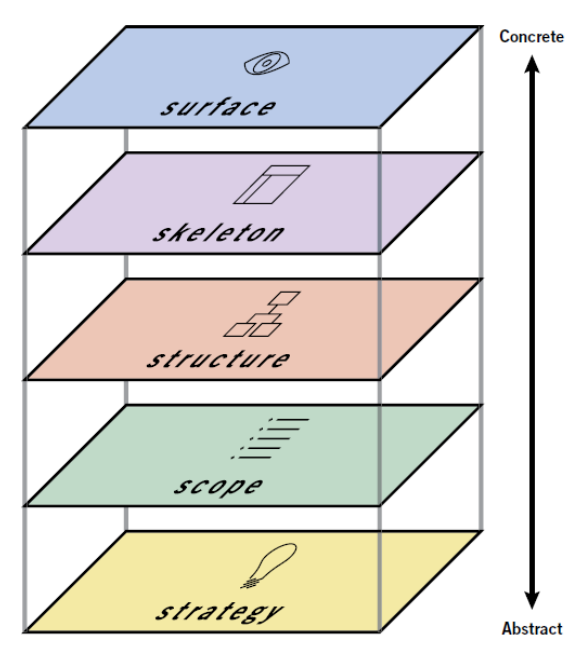

Na fase de estratégia 'Garret, 2003' declara que as necessidades e os objetivos precisam estar bem claros. Para tal, foram analisadas as necessidades do usuário por meio de pesquisas, como também os objetivos do aplicativo e por fim a estratégia a ser adotada. A pesquisa foi realizada seguindo os passos básicos que 'Unger, 2009' descreve, segundo o mesmo são necessários 5 passos que são: definir os grupos de usuários primários, planejar o envolvimento do usuário, conduzir a pesquisa, validar as definições do grupo e criar requisições de usuário.

Na Sequência 'Garret, 2003' define a fase de escopo, na qual determina-se o que incluir, como os conteúdos específicos necessários e as funcionalidades. A fase estrutural envolve o design de interação e a arquitetura da informação, nesta etapa vamos definir o que é essencial e como será incluído, vamos organizar, dividir e categorizar.

De acordo este método a próxima fase chamada de esqueleto é onde a função cria um 
formato, o conteúdo ganha forma e interagem por botões, imagens, textos, propondo que "uma interface de sucesso é aquela que o usuário percebe de forma imediata o que é mais importante".

O plano de superfície é como se fosse a maquiagem do esqueleto do produto, portanto nele importante valorizar os sentidos. (Garret 2003: 134-135). Alguns pontos que devem ser avaliados nesta estapa são: cor, contraste, tipografia, grid e a Consistência. As cores, segundo (Pavelecine, 2013) podem ser utilizadas para facilitar o entendimento e comunicar uma ideia. A cor a ser utilizada deve ser escolhida com precaução a fim de não se transmitir a mensagem errada.

Para 'Munari 2006, p. 339', citado por 'Pavelecine 2013: 27 ' "o contraste é uma regra muito antiga da comunicação visual, a qual é valorizada e intensificada através de duas formas de natureza oposta”. De acordo com 'Gomes Filho 2009 : 65' 'ergonomicamente, o contraste "proporciona melhor visibilidade, legibilidade e acuidade visual de sistemas de informação e, ainda, para codificação de sinais cromáticos e para chamar a atenção para dispositivos operacionais". O uso do contraste é uma ferramenta para tornar o sistema operacional mais atrativo e interessante para o usuário, quando o produto não possui esse contraste corre 0 risco de se tornar tedioso, pois não chama a atenção do usuário.

A tipografia é também parte integrante nesta etapa do projeto, alguns pontos importantes que devemos avaliar na escolha da tipografia são: Legibilidade, flexibilidade, elegância, leitura, carisma e adaptabilidade. É importante, portanto avaliar a tipografia no contexto no qual ela será incluída, considerando conteúdo, intenções e preferências pessoais (Lupton, 2014).

O grid é o que podemos chamar de wireframe que representa as etapas de estrutura e esqueleto da metodologia de 'Garret'. O wireframe refere-se ao esquema da página ou projeto da tela, o mesmo usa elementos simplificados para representar conteúdo básico que a tela possui. A consistência da navegação indica os caminhos previstos e coerentes que usuário poderá seguir pelo conteúdo (Lupton, 2014). Finalizando assim com a construção do caminho a ser seguido a fim de que o usuário chegue na informação desejada da maneira mais lógica e simples possível.

\section{Metodologia científica e metodologia de projeto}

$\mathrm{Na}$ construção do aplicativo turístico do município de Caruaru, utilizaremos o embasamento teórico como base de construção. Neste embasamento encontram-se a definição de comunidade surda, bem como a de turismo acessível e por fim as teorias de sistema da informação. Este trabalho foi feito a partir de pesquisas bibliográficas, livros, sites e artigos científicos. Nesta pesquisa optou-se por examinar um aplicativo de turismo existente e realizar testes com os surdos a fim de identificar suas falhas de acessibilidade.

Esta pesquisa se utiliza de uma abordagem qualitativa pois, durante os testes do aplicativo escolhido "Guia de Caruaru", ocorre uma entrevista semi-estruturada, como também são avaliadas observações adicionais que os usuários apontam durante a utilização do aplicativo.

Os estudos acerca da área de Design Digital evoluíram ao longo dos últimos 50 anos. Todavia, existe uma subárea de Design digital que envolve várias outras áreas e cujo estudo 
tornou a presente pesquisa multidisciplinar: é o estudo de aplicativos móveis para pessoas com limitações auditivas. Poder-se-ia partir apenas da área de usabilidade ou acessibilidade, mas para este público, tem-se particularidades que envolvem também Design da informação e de interação.

Dito isto, tem-se como referência um modelo de desenvolvimento, análise e avaliação de sistemas digitais, com foco em WEB design e outros sistemas, tais como softwares, etc. Para esta pesquisa, o objetivo foi desenvolver um aplicativo móvel que trouxesse um mapa turístico da cidade de Caruaru e que fosse direcionado a pessoas surdas. Com foco neste público, eis a descrição do estudo.

Em primeiro momento, foi realizada uma entrevista semi-estruturada, baseada nas orientações de 'Marcone e Lakatos 1998', onde a pesquisadora abordou e entrevistou um grupo de pessoas surdas, de uma determinada comunidade/ONG da cidade de Caruaru. As perguntas eram respondidas a partir da realização ou não das tarefas propostas em determinado aplicativo que não possui acessibilidade e observações adicionais que os usuários apontaram. As etapas desta entrevista foram: Entregar um smartphone com o aplicativo já instalado e aberto, e solicitar que o usuário realize as quatro tarefas pré-determinadas no intervalo de 10 minutos, neste tempo o entrevistador irá analisar se o entrevistado realizou ou não a atividade e responder o questionário.

A referida entrevista continha 4 perguntas, orientadas à investigação de fatores que interferem na utilização de determinado aplicativo móvel. Vemos que a entrevista só possui quatro perguntas pois conforme dito acima o foco da pesquisa é qualitativo e o objetivo destas perguntas é visualizar onde estão as dificuldades de utilização do aplicativo.

Com base nesta entrevista, tudo o que foi dito pelos entrevistados tornou-se uma base de dados para o desenvolvimento de um protótipo de um aplicativo móvel que continha um mapa turístico de Caruaru, para este público alvo. Deste modo, a interpretação destes dados que foram as respostas das entrevistas tornou-se os requisitos projetuais para que o método de 'Garret 2003' fosse aplicado, de fato. Logo, as respostas eram diretrizes.

\section{Dados obtidos com os questionários sobre um aplicativo de turismo não direcionado a surdos}

A Comunidade surda é o público alvo desta pesquisa, segundo 'Unger 2009' é necessário priorizar os atributos "que parecem ter maior impacto sobre o porquê e como um usuário potencial usaria o seu site ou aplicação". Para entender quais são esses atributos que a comunidade surda prioriza foram realizados questionários.

O questionário foi aplicado com 10 membros da comunidade surda de diversas faixas etárias de 14 a 56 anos. O pesquisador 'Nielsen 2001' apud 'Agner 2006' defende que "com apenas cinco usuários é possível identificar cerca de $75 \%$ dos problemas críticos de interface". Pensando nisso, o número de participantes foi de 10 membros pois para o interesse desta pesquisa o valor qualitativo sobrepõe o quantitativo.

Todos os integrantes da pesquisa usam smartphones diariamente. Os entrevistados foram submetidos ao uso de um aplicativo turístico da cidade chamado "Guia de Caruaru" que 
não possui nenhum tipo de acessibilidade, os mesmos deveriam executar tarefas predeterminadas. A seguir as telas do aplicativo utilizado:

Figura 3 - Telas do aplicativo analisado. Fonte: Guia Caruaru.

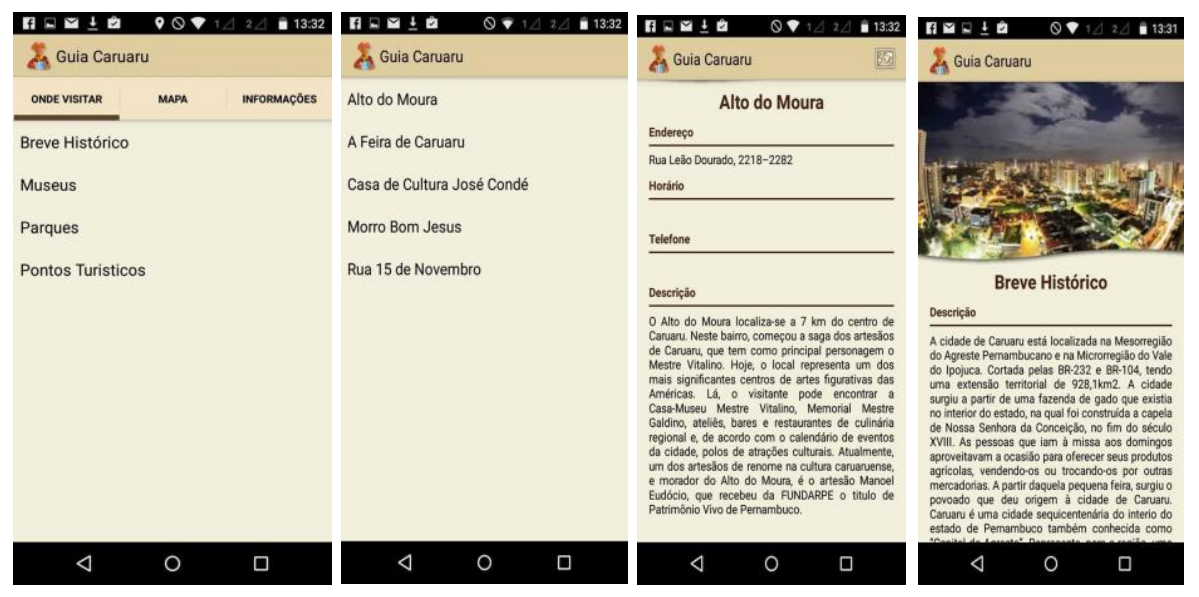

O questionário foi respondido pela entrevistadora, de acordo com a realização ou não determinada tarefa e com o auxílio de uma intérprete de LIBRAS. Abaixo segue os resultados da pesquisa:

A colocação 1 era: "Encontre as informações referentes ao Museu da Fábrica Caroá". A maioria não conseguiu realizar a tarefa, no sistema. A minoria que conseguiu utilizou-se como referência inicial a similaridade da palavra museu da pergunta para a partir desta informação adentrar na categoria e encontrar os museus disponíveis. Foi observado que a palavra museu não fazia parte do repertório dos mesmos, pois questionaram o significado da palavra.

A colocação 2 era: "Encontre o endereço do parque ambientalista Severino Montenegro". A maioria não conseguiu realizar a tarefa, no sistema. A minoria que conseguiu utilizou-se como referência inicial a palavra parque para a partir desta informação adentrar na categoria e encontrar os parques disponíveis. a palavra parque era de significado conhecido por uma minoria.

A colocação 3 era: "O breve histórico da cidade foi entendido?". A maioria não conseguiu entender o texto por completo e tentou fazer associações com a imagem acima do texto. A minoria conseguiu entender o texto em partes e tentou utilizar o auxílio da intérprete para entender o restante.

A colocação 4 era: "Encontre o horário de funcionamento do parque Baraúnas". A maioria não conseguiu realizar a tarefa, no sistema. A minoria que conseguiu utilizou-se como referência inicial a palavra parque para a partir desta informação adentrar na categoria e encontrar a palavra horário. A palavra parque era de significado conhecido pela minoria.

Em uma análise geral das informações colhidas, a maior parte dos entrevistados não conseguiu entender corretamente o significado das palavras, o que despendia bastante tempo a fim de encontrar o local solicitado por tentativa e erro. (Destes que não conseguiram encontrar o local solicitado, foram desconsideradas as tentativas posteriores, pois se ocorreu acerto não foi por entendimento e sim por tentativa e erro). Nas telas que possuíam textos longos o número de pessoas que conseguiram realizar a tarefa de compreender o que estava escrito no texto foi muito menor. Percebeu-se também que alguns informaram durante a entrevista que haviam entendido algo sem tê-lo entendido realmente, isto ocorre por receio de ser interpretado como alguém que não possui capacidade de entender o contexto de alguma situação. Todas as informações colhidas foram validadas através de uma intérprete de LIBRAS, para assegurar a pesquisa do que foi realmente entendido ou não. 


\section{Metodologia de projeto para a construção do protótipo do aplicativo para surdos}

Com base nas respostas dos entrevistados e as respostas não verbalizadas e percebidas pela entrevistadora, a prioridade do nosso público alvo é o uso de aplicativos que utilizem a LIBRAS na comunicação substituindo-se ao máximo as palavras escritas, isso influencia e incentiva diretamente o uso do aplicativo em detrimento de outros disponíveis que não possuem este diferencial, entre outros atributos que abordaremos adiante.

\section{Geração de um fluxograma de navegação para o aplicativo}

Abaixo segue o fluxograma de navegação criado. O resultado mais satisfatório para o público é um fluxograma leve e simples:

Figura 4 - Exemplo de fluxograma de navegação. Fonte: Própria autora.

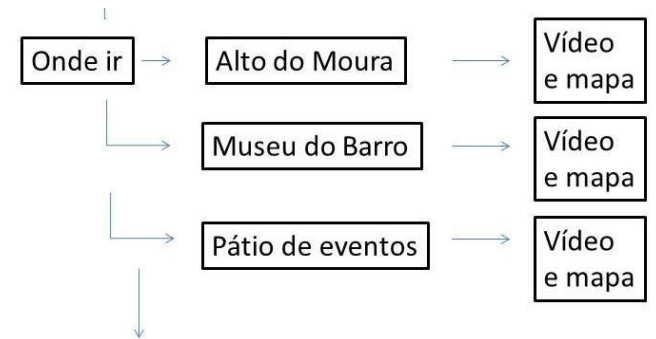

Mais opções...

\section{Geração de Vídeos}

Facilitar o deslocamento independente é a principal necessidade do aplicativo e o objetivo é tornar possível o entendimento através de vídeos de LIBRAS entre outras opções visuais como mapas, menus e pictogramas. Os vídeos em LIBRAS explicariam as opções de transportes disponíveis e informações básicas do local. O vídeo é construído a partir de um roteiro prédeterminado, após isso é gerado o arquivo de vídeo que será inserido no aplicativo. $O$ vídeo pode ser por exemplo feito a partir de aplicativos disponíveis no mercado que traduzem 0 português para a LIBRAS, conforme imagens a seguir:

Figura 5 - Imagens do aplicativo Hand Talk e Prodeaf. Fonte: Tech Apple

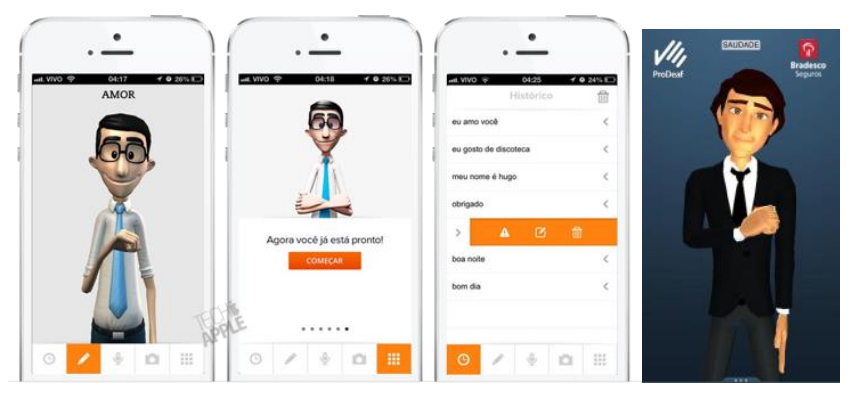

No entanto, as frases inseridas não seguem a estrutura da língua Portuguesa, é 
necessário adaptar as palavras a estrutura da LIBRAS para que a tradução seja eficiente. Este roteiro deve ser feito por um intérprete de LIBRAS que entende as peculiaridades da estrutura dessa língua.

Outra possibilidade é a gravação de um profissional intérprete de LIBRAS. Que possui a vantagem de ser mais fiel à realidade tanto nas traduções como nas expressões faciais. A imagem a seguir exemplifica esta possibilidade.

Figura 6 - Imagem de um intérprete de LIBRAS em tela de tablet. Fonte: Prodeaf.

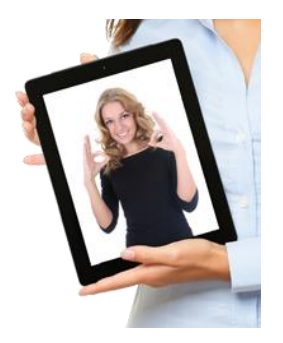

\section{Definição dos mapas}

Os mapas utilizados serão no padrão "Google maps" e irão definir a atual localização pelo GPS para criar uma rota ao local de destino de acordo com o transporte a ser utilizado. Caso o usuário não esteja em Caruaru e queira fazer uma simulação também é possível inserindo o local de saída desejado. Abaixo segue exemplo:

Figura 6 - Mapa. Fonte - Google maps.

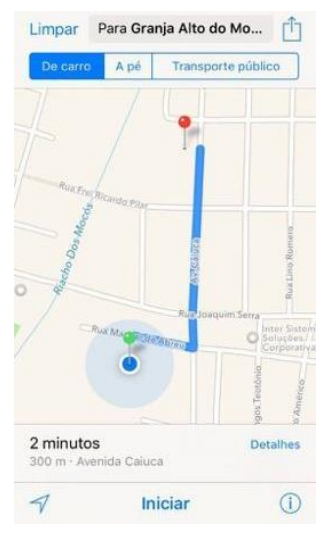

\section{Definição dos menus}

Já para os menus de opções utilizamos palavras de fácil entendimento como, por exemplo:

Onde ir, onde comer, onde ficar em substituição a palavras maiores e complexas que poderiam dificultar o entendimento, tornando as interações, rápidas e simples. Como explicado anteriormente, 'Cybis 2007', o menu pode minimizar as tarefas a serem realizadas pelo usuário se tornar o acesso rápido às opções utilizadas mais frequentemente. O menu é uma boa opção para a utilização em aplicativos móveis, em vez de digitações para pesquisas, digitação em telas pequenas só devem ser usadas em último caso, o usuário não deve despender muito tempo digitando o que deseja, o ideal é se possível ter as opções a disposição em menus. Podemos com isso reafirmar que menus são a melhor opção, levando em consideração que como visto na pesquisa o nosso público alvo, este público tem poucas habilidades de datilografia, ou seja, digitar os nomes dos locais para fim de pesquisa seria complicado e geraria várias falhas na busca. 


\section{Definição da tipografia}

Como visto anteriormente a tipografia é parte importante do projeto, para a escolha da tipografia foram avaliados os quesitos de legibilidade, flexibilidade, elegância, leitura, carisma, a adaptabilidade de acordo com o contexto a qual ela será inserida, considerando conteúdo da qual a mesma fará parte e intenções. Segundo 'Cybis 2007", as fontes sem serifa tem aparência mais leve, mas de difícil leitura em textos longos, para textos longos deve-se usar as fontes com serifa. Por tanto, a tipografia a ser escolhida precisa ser legível, porém, a mesma não precisa necessariamente ter boa leitura em textos longos, pois textos longos não existem no aplicativo. Seguindo estes critérios de avaliação a tipografia que escolhida e avaliada segundo nosso contexto foi a Amaranth, que se trata de fonte sem serifa.

Figura 7 - Tipografia Amaranth. Fonte: 2015 Própria autora.

\section{Amaranth}

\section{Definição dos pictogramas}

Os pictogramas são fáceis de serem compreendidos, pois não tem muitos detalhes, possuem no máximo duas cores e são representados por signos que são comuns. (Araújo, 2014), estes pictogramas já convencionados vão agir como coadjuvantes que agregados às palavras facilitarão o entendimento.

Foram também escolhidos alguns pictogramas da coleção "I love Caruaru" do designer Otávio Henrique. As ilustrações criadas nessa coleção representam os elementos, lugares e construções mais icônicos da cidade. (Gomes, 2015). Estes pictogramas em especifico serão utilizados para assimilação da forma do local na mente do usuário, até que em determinado ponto o mesmo já faça o reconhecimento automaticamente.

Figura 8- Coleção "I love Caruaru” de Ótavio Henrique Gomes (cedido pelo autor). Fonte: Gomes (2015)
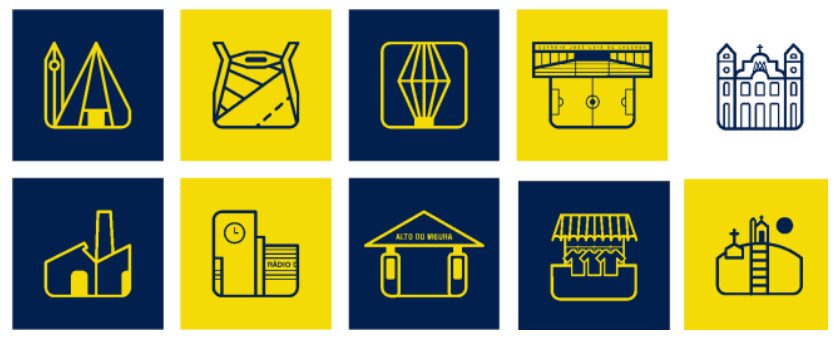

Os pictogramas são imagens produzidas "que remetem por mais remota que seja à aparência ou estrutura de algo real ou imaginado" 'Lima 2009'. Segundo 'Schiavenin, 2015' para o usuário interpretar os pictogramas é necessário somente a percepção do mesmo, a visão do pictograma faz com que compreendamos a informação, independente da língua que a pessoa fale. Esta assimilação ocorre devido ao repertório visual que possuímos.

\section{Definição de cores}

A cor azul foi selecionada por se tratar da cor representativa nacionalmente da comunidade surda de acordo com Dr. Ladd (surdo) e é usado em laço de fita na cor azul como símbolo nas comemorações da data no mês de setembro. 'Fraser 2012' explana que "[...] que o azul - o céu e do mar, por vastas extensões que oferecem uma percepção de liberdade e perspectiva - 
acalma as pessoas". Contudo, o autor também lembra que pode ser considerada uma cor "fria" e até mesmo "solitária". Já que a interpretação do azul depende bastante do contexto. Seja inserida também a cor amarela considerada uma "cor quente" que gera contraste e hierarquia, a cor amarela será aplicada nos pontos em que se deseja algo destacar no aplicativo, ou aqueles que devem chamar mais ainda a atenção do usuário. Abaixo seguem as cores utilizadas:

Figura 9 - Cores utilizadas. Fonte: Fonte: 2016 Própria autora

\begin{tabular}{|l|l|}
\hline Amarelo & C: $1 \mathrm{M}: 17 \mathrm{Y}: 90 \mathrm{~K}: 0$ \\
\hline C: $1 \mathrm{M}: 17 \mathrm{Y}: 90 \mathrm{~K}: 0$ \\
\hline C: $0 \mathrm{M}: 0 \mathrm{Y}: 0 \mathrm{~K}: 0$ \\
\hline
\end{tabular}

\section{Apresentação do Protótipo final}

Todos os requisitos estudados acima foram aplicados no layout do protótipo final. Abaixo segue as imagens das primeiras telas no exemplo do fluxo de navegação com destino ao ponto turístico Alto do Moura.

Figura 10 - A tela inicial do protótipo. Fonte:2016 Própria autora.

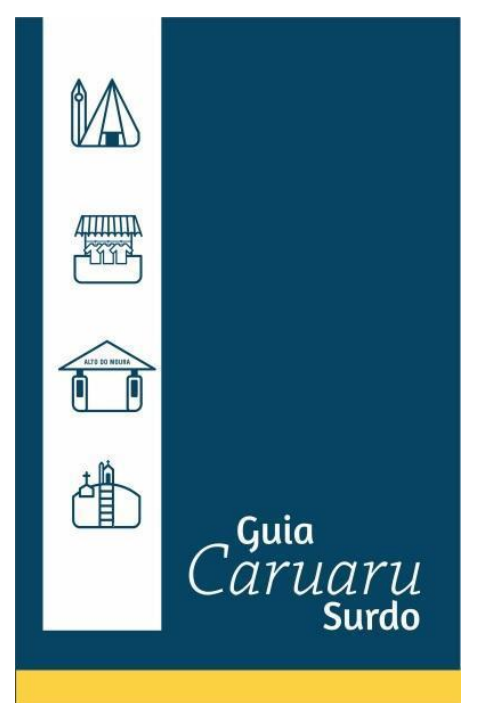

A tela inicial será a primeira a aparecer assim que o aplicativo estiver aberto e enquanto o restante dos recursos é carregado (como forma de feedback para o usuário, nela foram aplicadas as cores escolhidas para o aplicativo, laranja e azul. A disposição dos ícones e textos na tela foi pensada seguindo a linha de visualização diagonal padrão, da esquerda para direita e para baixo. 


\section{CIDI2017 ${ }^{8 \mathrm{n} C 1 D I}$

Figura 11 - Segunda tela do protótipo. Fonte:2016 Própria autora

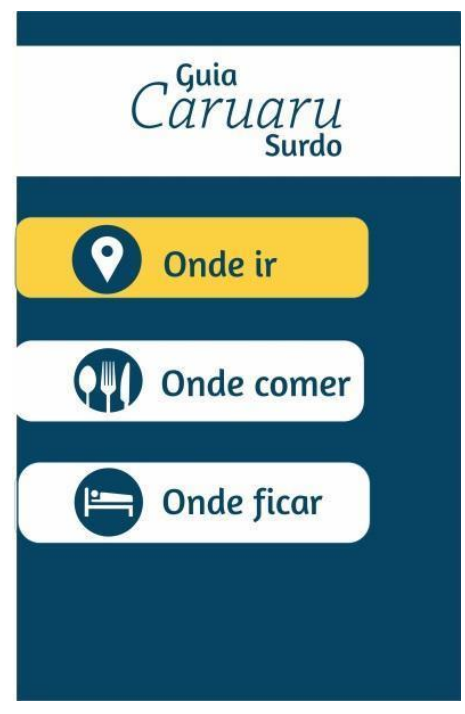

A tela possui, no topo, o nome do aplicativo em destaque, e logo abaixo o menu com três opções de fácil associação dentro de caixas com bordas arredondadas para assimilação com botões, além desse recurso, se o usuário tocar no botão ele muda de cor e vibra, valorizando os sentidos de visão e o tátil, o entendimento do que se irá encontrar ao clicar em cada caixa se torna simples pelo fato das palavras serem curtas e de uso corriqueiro, juntamente com o uso de pictogramas que agem em complemento. Após o usuário clicar na opção "onde ir" ele será conduzido para esta terceira tela, conforme imagem abaixo:

Figura 12 - Terceira tela do protótipo. Fonte:2016 Própria autora.

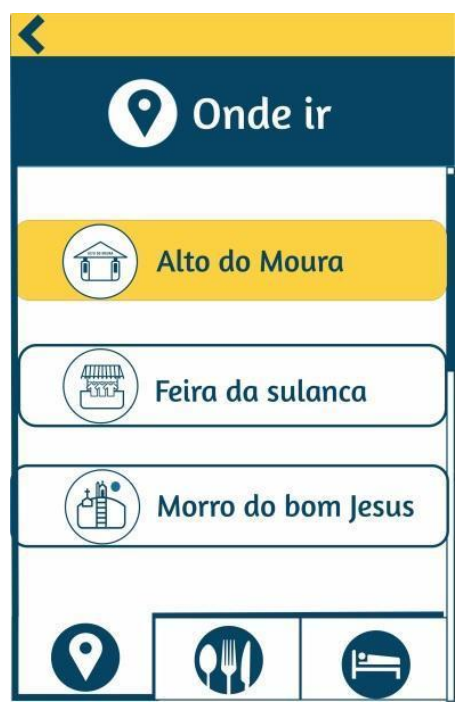

Nesta tela na parte superior tem em destaque um botão de voltar possibilitando que 0 usuário volte para a tela anterior, proporcionando sensação de autonomia ao mesmo. Logo 
abaixo o nome da página onde o usuário se encontra "Onde ir". Abaixo encontram-se os nomes dos pontos turísticos e os respectivos pictogramas. Este menu segue o padrão das demais telas, a fim de criar uma padronização e similaridade nas telas. No canto inferior encontram-se as mesmas três opções que da segunda tela; "onde ir", "onde comer" e "onde ficar", está opção fica disponível nesta e na próxima página e também gera autonomia, gerando um atalho que pode ser utilizado a qualquer momento que destaca também qual a página atual.

Figura 13 - Navegação no protótipo. Fonte:2016 Própria autora

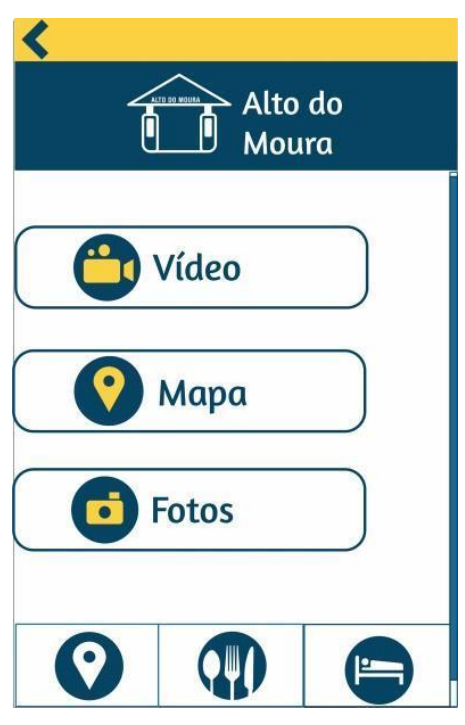

Na quarta tela aparece após o usuário clicar no destino escolhido, que nesse caso do exemplo é o Alto do Moura, a seta de voltar aparece novamente, o nome do local no topo da página seguindo o mesmo padrão da anterior, logo abaixo as caixas de vídeo, mapa e fotos, como exemplo na imagem a baixo:

Figura 14 - continuação da navegação no protótipo. Fonte:2016 Própria autora

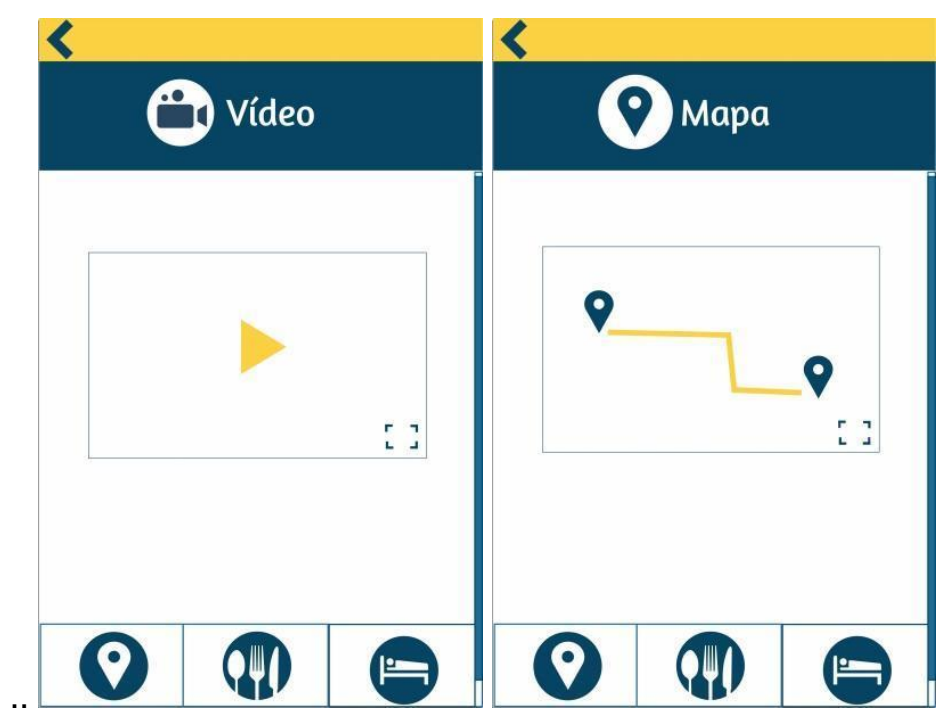

\section{Conclusão}


Após um longo estudo, atingimos os objetivos da pesquisa, visávamos elaborar um protótipo de um aplicativo turístico para surdos. O objetivo deste aplicativo é que com o seu uso, pessoas surdas possam ter independência para se locomover pela cidade, visitando pontos turísticos e usando apenas um smartphone, onde sem muita dificuldade e fácil manuseio o interessado pode obter todas as informações que precisa, em LIBRAS, tais como: localização, distância, meios de transporte e etc.

A fim de atingir tais objetivos, foram feitos levantamentos de autores de diversas áreas e contando com a colaboração dos próprios surdos nos questionários, entrevistas, testes e simulações. Nestes questionários detectamos quais são os requisitos projetuais desta comunidade para o produto projetado. Para aplicar estes questionários contamos com a ajuda de uma intérprete de LIBRAS, a presença da mesma, auxiliou no melhor entendimento das respostas apresentadas pelos surdos. Como resultado dos questionários, afirmamos que, a Língua Brasileira de sinais (LIBRAS) possibilita a melhor transmissão e entendimento da informação como também outros requisitos.

A metodologia de criação utilizada neste projeto foi a de Garret, à medida que aplicamos a metodologia, sentimos que a mesma é bem completa e que abrange todas as etapas do processo de criação. Como coadjuvantes desta metodologia utilizamos autores que agregaram conhecimentos complementares.

Acreditamos que com esse dispositivo a comunidade surda irá sentir-se prestigiada, visto que até então os surdos dependem quase que totalmente de um intérprete, que nem sempre é possível tê-lo. Sabemos que os surdos são pessoas que possuem inteligência, prova disto são os profissionais surdos nas mais diversas áreas de atuação, mostrando toda a capacidade cognitiva e altruísmo e, portanto, não aceitam mais serem discriminados, como acontecia anos e anos atrás, em uma sociedade medíocre e hipócrita, os surdos eram considerados como sub-raça e aberrações da natureza, graças a muita luta de estudiosos e da comunidade surda, hoje podemos dizer que a sociedade evoluiu bastante.

Por tudo isso, o futuro aplicativo fruto deste protótipo criado, visa tornar mais proveitosa a visita dessas pessoas, proporcionando-Ihes um melhor aproveitamento da atividade turística. E devido a boa impressão, ao regressarem às suas cidades de origem os mesmos tornem-se divulgadores destes benefícios encontrados em nossa cidade. Pois, além de voltar a visitar a cidade os mesmos trarão outras pessoas que por ventura também portadoras das mesmas necessidades. E nós como cidade receptora seremos denominadas como uma cidade mais humana e acolhedora. Deixando claro é que de extrema importância a continuidade da pesquisa sobre o tema.

\section{Referências}

ARAUJO, Caio. 2014. Infográficos por infográficos: Uma abordagem metodológica. Volta Redonda: Centro Universitário de Volta Redonda.

AGNER, L. 2006. Ergodesign e Arquitetura da Informação. Rio de Janeiro. Ed. Quartet.

BARBOSA, S. D. J.; SILVA, B. S. 2010. Interação Humano-Computador. Rio de Janeiro. Elsevier. 2010.

CYBIS, W. 2007. Ergonomia e Usabilidade. São Paulo: Ed Novatec.

FRASER, T. 2012. O essencial da cor no design. São Paulo: Editora Senac São Paulo.

FREIRE. L. 2015. Ergonomia Informacional. Notas de sala de aula não publicadas. Departamento de Design e Comunicação. Universidade Federal de Pernambuco.

GOMES, O. H. 2015. Ícones Caruaru [mensagem pessoal]. Mensagem recebida por <iaracassia93@gmail.com>, 20/06/2017.

GOMES, F. J. 2009. Gestalt do Objeto: Sistema de Leitura Visual da Forma. São Paulo: Escritura editora. 
LIMA, R. C. 2009. Análise da Infografia Jornalística. Dissertação de mestrado. Rio de Janeiro.

LUPTON, E. 2015. Tipos na Tela. Ed. Gustavo.

MARCONI, M. de A.; LAKATOS, E. M. 2003. Metodologia Científica 5ํo Edição São Paulo: Editora atlas.

MUNARI, B. 2006. Design e comunicação visual. Contribuição para uma metodologia didática. São Paulo. Martins Fontes.

PADOVANI, S. 2004. Apostila de acompanhamento ao módulo disciplinar. Curso de Especialização em Ergonomia, Universidade Federal do Amazonas.

PAVELECINE, M. 2013. Proposta de uma interface gráfica para um sistema de gerenciamentos de eventos, Porto Alegre.

SURDOSOL 2015. Programação do São João em Caruaru conta com interpretação em Libras. In: Home: Surdosol. <http://www.surdosol.com.br/programacao-do-sao-joao-emcaruaru-conta-com-interpretacao-em-libras/>. 26/09/2015.

SILVA, B. S.; BARBOSA, S. D. J. 2010. Interação humano-computador-Rio de Janeiro: Elsevier.

UNGER, R.; CHANDLER, C. 2009. A experiência do usuário (UX) para projetistas de conteúdo digital, aplicações e web sites. 1. ed. Rio de Janeiro: Editora alta books.

lara Florêncio - Unifavip/Devry - Brasil - iaracassia93@gmail.com

Diogo Cavalcanti - UFPE/CAA Núcleo de Design - Brasil - diogoccavalcanti@gmail.com

Luciana Freire - UFPE/CAA Núcleo de Design - Brasil - lucianafreire@gmail.com 